\title{
Targeted inhibition in tumors with ALK dependency
}

\author{
This article was published in the following Dove Press journal: \\ Lung Cancer:Targets and Therapy \\ 9 January 2013 \\ Number of times this article has been viewed
}

\section{Eunice L Kwak Jeffrey W Clark Alice T Shaw}

Massachusetts General Hospital Cancer Center, Boston, MA, USA
Correspondence: Eunice L Kwak Massachusetts General Hospital Cancer Center, 55 Fruit St, Yawkey Building, Boston, MA 02।I4, USA

Email ekwak@partners.org
Abstract: The oncogenic function of gene translocations involving the anaplastic lymphoma kinase $(A L K)$ was first reported in rare subtypes of non-Hodgkin's lymphoma almost two decades ago. More recently, aberrant ALK signaling was found to be an oncogenic driver in subsets of non-small cell lung cancer (NSCLC), particularly in patients with little or no tobacco smoking history. The advent of molecularly targeted therapies that inhibit ALK has allowed the pairing of ALK inhibitors such as crizotinib as treatment for ALK-positive NSCLC, yielding dramatic responses and long-term disease control. The clinicopathologic features of ALK-driven NSCLC, the clinical development of ALK inhibitors, and the genetic determinants of acquired resistance to ALK inhibition are among the topics covered in this review.

Keywords: targeted inhibition, tumors, ALK dependency

\section{Introduction}

Lung cancer has traditionally been regarded as a collection of diseases defined by characteristic histologic features, primarily encompassed by the classifications of adenocarcinoma, squamous cell carcinoma, large cell carcinoma, and small cell carcinoma. However, an appreciation for the importance of genetic subtypes in non-small cell lung cancers (NSCLC) was ushered in by the discovery of activating mutations (eg, del746_A750 or L858R) in the epidermal growth factor receptor gene $(E G F R)$ in a subset of NSCLCs. ${ }^{1-3}$ This was the first understanding that some lung cancers could be dependent on one gene or signaling pathway for the maintenance of the malignant phenotype, a phenomenon termed "oncogene addiction". ${ }^{4}$ The dependency of these mutant NSCLCs on aberrantly active EGFR signaling confers exquisite sensitivity to inhibition by small molecule tyrosine kinase inhibitors, such as erlotinib and gefitinib. Previous to this discovery, many years of clinical investigation had been spent without an appreciation for the role of tumor genetics as a powerful predictor of patient outcome upon treatment with erlotinib and gefitinib.

Remarkably, another genetic subtype of lung cancer emerged with the discovery of oncogenic anaplastic lymphoma kinase (ALK) fusion genes in NSCLC. ${ }^{5}$ ALK is a member of the insulin receptor superfamily of receptor tyrosine kinases. In normal human physiology, ALK expression is limited to the adult brain, and the function is unclear, although it may be involved in specific aspects of neuronal development. ${ }^{67}$ Preclinical studies in ALK knockout mice have identified a role for ALK in the hippocampus, particularly involving neurogenesis and spatial memory. ${ }^{8,9}$ The role of ALK in oncogenesis was first established by the cloning of the fusion gene submit your manuscript | www.dovepress.com

Dovepress

http://dx.doi.org/10.2147/LCTT.S16313
Lung Cancer:Targets and Therapy 2013:4 I-8

(C) 2013 Kwak et al, publisher and licensee Dove Medical Press Ltd. This is an Open Access article which permits unrestricted noncommercial use, provided the original work is properly cited. 
nucleophosmin- $A L K$ in anaplastic large cell lymphoma. ${ }^{10}$ While ALK fusions can result from translocation at multiple chromosomal sites, the NPM-ALK $\mathrm{t}(2 ; 5)$ translocation occurs in approximately $80 \%$ of cases of anaplastic large cell lymphomas that harbor ALK activation. In anaplastic large cell lymphoma, ALK is activated via proximity to strong $5^{\prime}$ promoters, and/or through inappropriate oligomerization leading to constitutive ALK activation. ${ }^{11}$ A role for ALK in lung cancer was discovered when NIH3T3 cells were infected with a retroviral cDNA expression library prepared from a clinical lung adenocarcinoma specimen. Recovery of cDNA from one of the transformed foci revealed a fusion gene encoding a portion of the echinoderm microtubule associated protein-like protein (EML4) fused to the tyrosine kinase domain of $A L K .{ }^{5}$ EML4-ALK fusions result from rearrangement within chromosome 2 (inv (2)(p21p23)) and fusion of the $5^{\prime}$ portion of EML4 with the $3^{\prime}$ portion of $A L K$. The resulting chimeric protein contains an $\mathrm{N}$-terminus derived from EML4 and a C-terminus that contains the entire intracellular tyrosine kinase domain of ALK. Multiple forms of the EML4-ALK fusion have since been identified, all of which encode the same cytoplasmic portion of ALK, but contain varying lengths of EML4. ${ }^{12,13}$ In NSCLC, ALK may fuse with a variety of other partners including TFG (TRK-fused gene), KIF5B, PTPN3, and KLC1, although these fusion products are comparatively rare. ${ }^{14-17}$

Multiple centers have since screened retrospective series of NSCLCs for the presence of $A L K$ rearrangements using multiple diagnostic approaches. Several clinicopathologic features have emerged as characteristic for $A L K$ gene rearrangement, and are discussed as follows.

\section{Age}

The presence of ALK fusion proteins is associated with a relatively young population of NSCLC patients. A set of 266 primary NSCLCs from Chinese patients was analyzed by reverse transcriptase-polymerase chain reaction and sequencing, as well as immunohistochemistry. The median age of 209 patients with adenocarcinoma histology was 64 years, which was also the median age of patients whose tumors were negative for ALK, while the median age of ALK-positive cases was 59 years. ${ }^{18}$ Similarly, in another series, EML4-ALK tumors were identified in patients with an average age of 56 years versus 64 years for EML4-ALK-negative patients. ${ }^{19}$ Shaw et al reported a median age of 52 years for patients with $A L K$-rearranged tumors as compared with a median age of 64 years in patients with wild-type tumors. ${ }^{20}$ Similar results were reported by Rodig et al. ${ }^{21}$

\section{Smoking}

ALK fusions in NSCLC have been detected in tumors from both smokers and nonsmokers. ${ }^{18}$ However, multiple studies have observed that EML4-ALK is strongly associated with a history of never or light smoking. ${ }^{18-24}$ In one of these series, a $>10$ pack-year smoking history was seen in only four of 47 (9\%) ALK-positive patients. ${ }^{20}$

\section{Tumor histology}

EML4-ALK gene fusions have been identified predominantly in NSCLCs with adenocarcinoma histology. In the series from Wong et al, 11 of 13 EML4-ALK-positive cases were found in 209 adenocarcinomas, while the remaining two cases were classified as "other" histology. ${ }^{18} \mathrm{Kim}$ et al identified $A L K$ rearrangement by fluorescence in situ hybridization (FISH) in 19/465 cases of lung cancer, with 18 positive cases occurring in adenocarcinomas and one case classified as "other". ${ }^{25}$ Interestingly, EML4-ALK-positive cases are significantly more likely than EGFR mutant or wild-type tumors to have a solid pattern with abundant signet ring cells, ${ }^{20,21,26,27}$ although the biological or clinical significance of signet ring cells in EML4-ALK lung cancers is unclear. Another characteristic of ALK-positive NSCLCs is correlation with thyroid transcription factor-1 positivity, suggesting that these cancers may have a terminal respiratory unit etiology. ${ }^{19}$

\section{Prevalence}

In the initial report by Soda et al, 75 NSCLCs in Japanese patients were screened for $E M L 4-A L K$ by reverse transcriptase polymerase chain reaction, with identification of the fusion gene in five of $75(6.7 \%)$ cases. ${ }^{5}$ Institutional series have reported ALK fusions in similar percentages of unselected NSCLC patient populations. Several studies in Asian lung cancer populations have identified EML4$A L K$ in $4 \%{ }^{25}$ and $5.3 \%{ }^{18}$ of NSCLCs, and $4.3 \%$ of lung adenocarcinomas. ${ }^{19}$ Similarly, $A L K$ rearrangements were identified in 5.6\% (20/358) of lung adenocarcinomas from a Western patient population. ${ }^{20}$ Despite its rarity, the identification of $A L K$-rearranged tumors can be facilitated through enrichment using the clinicopathologic characteristics noted above. For instance, in a cohort of 141 NSCLC patients enriched to identify tumors with $A L K$ rearrangement or $E G F R$ mutation, $13 \%$ harbored $E M L 4-A L K$, and $22 \%$ harbored an activating $E G F R$ mutation, and these mutations were mutually exclusive. ${ }^{20}$ However, subsequent studies have reported concurrent $E G F R$ mutations and $A L K$ rearrangements in rare NSCLC tumors. ${ }^{28}$ In the cohort of 141 NSCLC patients, the percentage of $E M L 4-A L K$ positivity increased to $33 \%$ in 
patients who were never/light smokers and whose tumors did not contain EGFR mutations. ${ }^{20}$

\section{Cellular pathways involved in ALK signaling}

Wild-type ALK is a receptor tyrosine kinase belonging to the insulin receptor superfamily, and ligand binding leads to dimerization and kinase activation. $A L K$ fusion genes encode proteins that generally reside in the cytoplasm rather than in the plasma membrane, and these fusion proteins are constitutively active independent of ligand. ALK activation results in phosphorylation on Y1604, and in turn triggers multiple downstream signaling pathways, including those for RAS/MEK/ERK, JAK/STAT, and PI3K. Roles for each of these pathways have been demonstrated for $N P M-A L K$ in anaplastic large cell lymphoma. ${ }^{29}$ In the case of EML4-ALK, in vitro studies have demonstrated activation of MEK/ERK signaling, with some studies also indicating roles for STAT3 or PI3K/AKT pathways. ${ }^{23,30-32}$

In the setting of anaplastic large cell lymphoma, preclinical work had explored the ability of selective ALK inhibition to affect tumor growth. Small hairpin RNAs against the catalytic domain of ALK led to apoptosis and tumor regression in ALK-positive anaplastic large cell lymphoma cell lines, demonstrating the promise of ALK inhibition as a potential therapeutic strategy in patients with this disease. ${ }^{33}$ Subsequently, small molecule compounds of the diaminopyrimidine and aminopyrimidine classes (TAE684 and PF02341066) were generated ${ }^{34,35}$ and shown to target ALK selectively in vitro. ${ }^{36}$ PF-02341066, (R)-3-[1-(2,6-dichloro3-fluoro-phenyl)-ethoxy]-5-(1-piperidin-4-yl-1H-pyrazol4-yl)-pyridin-2-ylamine (subsequently termed crizotinib) was identified as an inhibitor of the ALK and mesenchymalepithelial transition factor (c-MET) tyrosine kinases through biochemical screens. In cell-based assays, crizotinib inhibited the tyrosine phosphorylation of $N P M-A L K$ with an $\mathrm{IC}_{50}$ of $24 \mathrm{nmol} / \mathrm{L}$ in two anaplastic large cell lymphoma cell lines, Karpas 299 and SU-DHL-1. Crizotinib inhibited wild-type and activated MET with an $\mathrm{IC}_{50}$ of $11 \mathrm{nmol} / \mathrm{L}$ across a panel of multiple cell lines, and was found to be selective for ALK and MET over a panel of more than 100 other kinases. ${ }^{36}$ In addition, crizotinib has subsequently been found to have significant activity against ROS1 kinase. ${ }^{37}$

\section{Clinical experience with ALK inhibition in lung cancer}

A first-in-human Phase I clinical trial of crizotinib in patients with advanced solid tumors was initiated in 2006 at three US institutions. Using a standard $3+3$ dose-escalation design, the trial established continuous twice-daily administration of $250 \mathrm{mg}$ crizotinib as the recommended Phase II dose. The drug was well tolerated, with mild gastrointestinal toxicities being the most common drug-related adverse events. ${ }^{38}$ The dose-escalation portion of the trial was in progress at the time when EML4-ALK was first discovered in NSCLC. ${ }^{5}$ At that time, under an institutional research protocol, early efforts were being made to screen clinical NSCLC samples for the $A L K$ fusion gene by FISH. Early indications of the activity of crizotinib were observed when two NSCLC patients who had progressed on multiple prior therapies for advanced disease, and whose tumors harbored $A L K$ gene rearrangement, experienced marked symptomatic improvement while being treated on the dose-escalation trial. ${ }^{38}$

This prompted expansion of the Phase I trial to include five additional investigational sites (representing the US, Australia, and Korea), and large-scale screening of NSCLCs for $A L K$ gene rearrangements by FISH was undertaken. By a data cutoff of April 2010, approximately 1500 NSCLC tumors had been screened for $A L K$ gene rearrangement, and 82 patients with $A L K$-rearranged tumors were enrolled into an expansion cohort of the Phase I clinical trial receivingcrizotinib $250 \mathrm{mg}$ twice daily. ${ }^{39}$ The data from this ongoing trial were subsequently updated to include 119 ALK-positive NSCLC patients enrolled with a data cutoff of October 29, $2010 .{ }^{40}$ The baseline clinicopathologic features that emerged from this trial reflected the unique characteristics previously reported in NSCLC tumors with $A L K$ gene rearrangement. Of the 119 patients enrolled on trial, the median age was 51 (range 21-79) years. A history of light or never smoking characterized the majority of patients enrolled on the crizotinib study, with $72 \%$ of enrolled patients having a history of never smoking. Ninety-seven percent of the 119 enrolled NSCLC patients with $A L K$ gene rearrangements had tumors with adenocarcinoma histology, frequently with the presence of signet ring cells. ${ }^{40}$

In the initial report of 82 patients with $A L K$-rearranged NSCLCs treated with crizotinib, the response rate was 57\%, with multiple patients experiencing clinical improvement and disease shrinkage within several weeks of starting drug. ${ }^{39}$ In the updated series of 119 patients, $86 \%$ of whom had received at least one prior line of therapy for advanced disease, 116 patients evaluable for response demonstrated an overall response rate of $61 \%$ (95\% confidence interval [CI] 52-70) with 69 patients achieving a partial response. A further 31 patients experienced stable disease as their best response. By the data cutoff, median progression-free 
survival in this heavily pretreated cohort of 119 patients was 10.0 months (95\% CI 8.2-14.7) with 50 events (42\%; 40 progressive disease events), 69 patients (58\%) censored, and 59/69 (86\%) in follow-up for progression-free survival. ${ }^{40,41}$

Among the 119ALK-positive NSCLC patients, crizotinib was generally well tolerated. Adverse events were usually grade 1 or grade 2, and consisted of visual effects [mostly trails of light at times of light accommodation (62\%), nausea (49\%), diarrhea (43\%), vomiting (35\%), and edema (28\%)]. Increases in liver function tests were seen, particularly affecting alanine transaminase. These occasionally reached grade 4 in severity but were reversible upon cessation of the study drug. Most patients were able to restart crizotinib at a lower dose without recurrence of dose-limiting transaminitis. ${ }^{40}$

Given the role of $A L K$ rearrangement as a predictive marker of crizotinib response in NSCLC, the effect of crizotinib on overall survival was evaluated in a 30-patient subgroup of the originally reported Phase I cohort of 82 ALK-positive NSCLC patients receiving crizotinib. ${ }^{41}$ The overall survival of these patients was compared with that of 23 patients with ALK-positive advanced NSCLC from the US and Australia who had received any secondline treatment, but had not received crizotinib, as well as to a group of ALK-negative/EGFR mutation-negative control patients. Because patients in the comparison groups were identified from non-Korean sites, the 30 patients with crizotinib-treated ALK-positive tumors did not include those patients that had been treated at the Korean Phase I institution, and furthermore represented only those patients treated in the second-line or third-line treatment setting. At the time of reporting, the median overall survival of crizotinib-naïve patients was 6 months, while the median overall survival of the crizotinib-treated cohort had not yet been reached (95\% CI of 14 months to not reached). As compared with patients having tumors lacking $A L K$ rearrangement or $E G F R$ mutation, there was no statistically significant difference in survival for the crizotinib-naïve ALK-positive disease group, suggesting that crizotinib treatment improves outcomes in a subset of lung cancers that would otherwise have a poor prognosis. ${ }^{41}$ The caveat to this analysis is its retrospective nature; however, the widespread availability of crizotinib so soon after identification of the role of ALK in NSCLC (see below) has rendered a retrospective analysis the only manner in which to evaluate a crizotinib-naïve ALK-positive group of NSCLC patients. Interestingly, a retrospective analysis of PFS in crizotinibnaïve patients treated with pemetrexed found that patients with ALK-positive NSCLCs experienced significantly longer progression-free survival than patients with ALKnegative tumors, indicating that, while not prognostic, ALK positivity may be a predictor of benefit from pemetrexed as well as crizotinib. ${ }^{42}$ A larger retrospective study has since demonstrated that ALK-positive and ALK-negative NSCLC patients have similar outcomes after pemetrexed-based therapy, although nonsmoking status may be predictive of benefit from pemetrexed. ${ }^{43}$

The success of the expansion cohort of ALK-positive NSCLCs treated with crizotinib led to the implementation of Phase III trials in the second-line and first-line setting, randomizing ALK-positive NSCLC patients to crizotinib treatment versus standard chemotherapy. The second-line trial has reached its goal accrual, and the results have been presented at the European Society of Medical Oncology congress in 2012. In 2011, on the basis of the response rate seen in 255 patients from the Phase I trial and a single-arm Phase II trial (NCT00932451), crizotinib received accelerated US Food and Drug Administration FDA approval in patients with advanced NSCLC harboring ALK rearrangement, along with a companion diagnostic test for ALK rearrangement.

\section{Molecular diagnosis of ALK rearrangement}

FISH has been used as the diagnostic method in all of the crizotinib studies. However, a variety of diagnostic approaches have been developed to identify activated ALK, including reverse transcriptase polymerase chain reaction and immunohistochemistry, in addition to in situ hybridization (FISH or chromosomal in situ hybridization). The approach of reverse transcriptase polymerase chain reaction and direct sequencing allows resolution of the genomic structure of EML4-ALK and has identified multiple isoforms of the fusion gene. The predominant isoforms, sometimes referred to as variant 1 and variant 2, arise through fusion of intron 13 of EML4 to intron 19 of $A L K$, and from fusion of EML4 intron 20 to $A L K$ intron 19 , respectively. Other isoforms arise through fusion of intron 6 of EML4, ${ }^{12}$ as well as exon 2 and exon 14 of EML4..$^{15,18}$ Although reverse transcriptase polymerase chain reaction is sensitive, provides more detail about EML4-ALK structure, and has even been used in sputum samples to detect rearrangement, the widespread use of this approach is limited by its dependence on sample quality, which is a consideration when using archival paraffin-embedded specimens. FISH uses two fluorescently labeled probes that flank the break point of the EML4 and $A L K$ fusion gene (Vysis LSI $A L K$ dual-color, 
break-apart probe, Abbott Laboratories, Abbott Park, IL), giving rise to signals that can be identified as split or isolated (indicating EML4-ALK rearrangement) or superimposed (indicating wild-type status). ${ }^{20}$ This analysis can be performed on archival paraffin-embedded tumor specimens, making it amenable to routine clinical use. However, interpretation of FISH results can be challenging, requiring experience in the interpretation of fluorescence microscope images in samples in which only a subset of cells may be evaluable for split signals. Because EML4-ALK is not expressed to a significant extent in normal tissues, immunohistochemistry for expression of the fusion protein is an attractive approach that enables analysis of paraffin-embedded tumor specimens in a fashion already routine in clinical practice. In one study, Kim et al compared chromosomal in situ hybridization with immunohistochemistry using an antibody to ALK (Novocastra Laboratories Ltd, Newcastle-upon-Tyne, UK) and found the two methods to be strongly correlated. ${ }^{25}$ Furthermore, intercalated antibodyenhanced polymer methods have been used to improve the sensitivity of immunohistochemistry. ${ }^{15}$ Because US Food and Drug Administration approval for crizotinib was granted using the Vysis probe for FISH as the approved companion diagnostic, FISH is the diagnostic method of choice at this time. Recently, improved antibodies have become more available and may favor the use of immunohistochemistry in the future.

\section{Resistance}

While FISH or immunohistochemistry is adequate to diagnose ALK-positive disease, the utility of reverse transcriptase polymerase chain reaction and direct sequencing will become more important as we seek to learn more about molecular determinants of response and resistance to targeted ALK inhibitors. The majority of patients treated with crizotinib experience disease shrinkage or stabilization, and progression-free survival exceeds what would be expected with standard chemotherapy. However, acquired resistance to crizotinib challenges the further management of these patients. In addition, primary refractoriness to crizotinib limits the treatment in a small percentage of patients with ALK-positive tumors. Mechanisms of resistance are the subject of intensive research, and multiple mechanisms have been described. Resistance mutations within EML4-ALK were first reported by Choi et al, who identified two subpopulations of cancer cells from the pleural effusion of a patient who initially experienced disease shrinkage on crizotinib, but then developed resistance to treatment. One subclone of resistant cells harbored a $4374 \mathrm{G} \rightarrow$ A substitution, resulting in a $\mathrm{C} 1156 \mathrm{Y}$ amino acid change adjacent to the $\mathrm{N}$-terminal of the predicted helix alpha $\mathrm{C}$ as well as close to the upper edge of the ATP-binding pocket in the fusion protein. The other mutation was found at L1196M, located at the bottom of the ATP-binding pocket, in a position analogous to the "gatekeeper" position previously found in chronic myelogenous leukemia with $B C R-A B L$ (T315I) resistant to imatinib ${ }^{44}$ and in EGFR (T790M) resistant to erlotinib. ${ }^{45}$ Doebele et al reported multiple mechanisms of resistance identified in 11 patients who had developed disease progression after initial response to crizotinib treatment, including: a new mutation, G1269A, found within the kinase region of ALK in two patients; a copy number gain seen in two patients (5-fold and >4-fold); the presence of an EGFR L858R mutation, despite ALK positivity in the original diagnostic transbronchial biopsy specimen; and several instances of $\mathrm{K}$-ras mutations in codon $12 .{ }^{46}$ Sasaki et al identified an L1152R mutation in the pleural fluid of a patient with NSCLC who progressed after initial disease shrinkage on crizotinib biopsied post-progression. ${ }^{47}$ This L1152R mutation had not been detected in the original tumor specimen prior to crizotinib treatment. In a cell line generated from the pleural fluid tumor cells containing L1152R, roles for activation of MET and EGFR signaling as a resistance mechanism were also identified. While crizotinib was able to inhibit phosphorylation of MET, EGFR activation appeared to be stimulated by the ability of this cell line to secrete amphiregulin, and required concurrent treatment with a pan-ERBB inhibitor to inhibit EGFR phosphorylation. ${ }^{47} \mathrm{~A}$ role for epidermal growth factor-mediated signaling in ALK-positive NSCLC tumor cell lines resistant to crizotinib was also demonstrated by Tanizaki et al. ${ }^{48}$ Activation of these pathways through endothelial and fibroblast secretion of EGFR and MET ligands has also been demonstrated, suggesting that paracrine signals from tumor microenvironments may also contribute to resistance. ${ }^{49}$

Additional kinase domain mutations have been identified by Katayama et al, including G1202R, S1206Y, and a threonine insertion mutation, 1151Tins. In vitro, cell lines engineered to express the kinase domain mutations C1156Y, L1196M, L1152R, G1202R, S1206Y, and 1151Tins were highly resistant to crizotinib at concentrations that inhibited intact EML4-ALK. ${ }^{31,46,50}$ Interestingly, distinct mutations possessed differential degrees of in vitro resistance or sensitivity to newer second-generation ALK inhibitors, suggesting that there may be clinical implications to the choice of ALK inhibitor used to treat patients. Nonetheless, preliminary results from the Phase I study of the potent, selective ALK inhibitor LDK378 demonstrated a response rate of $81 \%$ 
(21/26 cases) in ALK-positive NSCLC patients who had previously progressed on crizotinib. While the mechanisms of acquired resistance to crizotinib were not presented with these data, the impressive activity seen in this trial suggests the potential utility of LDK378 across a variety of resistance mutations in $A L K .^{51}$

Other resistance mechanisms that have been identified include $A L K$ gene amplification and KIT gene amplification, ${ }^{50}$ pointing to the diversity of acquired resistance mechanisms seen in ALK-positive NSCLC and to the future challenges in designing effective single-agent and combination treatment regimens. Importantly, ALK is a HSP90 client protein; HSP90 inhibition has activity against $A L K$-rearranged $\mathrm{NSCLC}^{52}$ and was found by Katayama et al to be active against the various kinase domain resistance mutants tested in vitro. ${ }^{50}$ Therefore, HSP90 inhibition may be a promising alternative strategy to treat or even prevent the emergence of resistance.

\section{ALK in other diseases}

While the preponderance of recent data comes from NSCLC, the therapeutic potential of ALK inhibition is relevant to a variety of other tumor types as well. In anaplastic large-cell lymphoma, the disease in which ALK molecular abnormalities were first identified, crizotinib has led to marked responses in ALK-positive relapsed chemotherapy-refractory disease. ${ }^{53}$ Crizotinib has also demonstrated activity in a case of an inflammatory myofibroblastic tumor harboring a RANBP-ALK fusion..$^{54}$ In neuroblastoma, activating $A L K$ mutations have been identified in both sporadic and familial cases. In vitro data suggest that these tumors may also be sensitive to ALK inhibitors, and crizotinib is being evaluated in a clinical trial enrolling neuroblastoma patients. ${ }^{55-57}$ Whether aberrant ALK has therapeutic implications for more common malignancies other than NSCLC has yet to be determined. ALK fusion has been rarely identified in renal cell cancers, ${ }^{58}$ and ALK fusions in breast and colon cancers have been described. ${ }^{59}$ Screening of clinical colorectal specimens by FISH has not supported this finding, although increases in gene copy number were seen. ${ }^{60}$ Next-generation sequencing may provide additional insights into the role of ALK in colorectal cancer. ${ }^{61} A L K$ gene amplification was reported in approximately $75 \%$ of patients in inflammatory breast cancer, and enrollment of such patients into clinical trials of ALK inhibitors is ongoing. .1,62 $^{2}$

\section{Conclusion}

Although the role of activated ALK as a driver of oncogenesis has been known since the discovery of $N P M-A L K$ in anaplastic large cell lymphoma, its role in NSCLC and the clinical availability of selective inhibitors has brought ALK to the forefront of clinical investigation. The activity of crizotinib in NSCLCs that have been screened for $A L K$ gene rearrangement has demonstrated that prospective molecular analyses in the early phases of clinical trials can identify the tumors most sensitive to targeted therapies and facilitate the development of new agents for those patients most likely to benefit. As the role of ALK is explored in additional tumor types, there will likely be other settings in which the success of crizotinib in $A L K$-rearranged NSCLC is duplicated.

As with all cancer therapies, the acquisition of resistance is a challenge to the ongoing successful treatment of patients with $A L K$-rearranged NSCLC. Recent data point to a variety of mechanisms of resistance with potentially multiple implications for therapy. As crizotinib resistance emerges, subsequent options for treatment may include second-generation ALK inhibitors such as LDK378, combinations of targeted agents, or HSP90 inhibitors. The optimal role for these approaches has yet to be determined, but further study will rely upon rebiopsy of resistant tumors and molecular analyses of these specimens. In NSCLC, as in other diseases, there is still much to be learned about ALK.

\section{Disclosure}

The authors report no conflicts of interest in this work.

\section{References}

1. Lynch TJ, Bell DW, Sordella R, et al. Activating mutations in the epidermal growth factor receptor underlying responsiveness of non-small-cell lung cancer to gefitinib. $N$ Engl J Med. 2004;350:2129-2139.

2. Paez JG, Jänne PA, Lee JC, et al. EGFR mutations in lung cancer: correlation with clinical response to gefitinib therapy. Science. 2004;304: $1497-1500$.

3. Pao W, Miller V, Zakowski M, et al. EGF receptor gene mutations are common in lung cancers from "never smokers" and are associated with sensitivity of tumors to gefitinib and erlotinib. Proc Natl Acad Sci USA. 2004;101:13306-13311.

4. Weinstein IB. Cancer. Addiction to oncogenes - the Achilles heal of cancer. Science. 2002;297:63-64.

5. Soda M, Choi YL, Enomoto M, et al. Identification of the transforming EML4-ALK fusion gene in non-small cell lung cancer. Nature. 2007; 448:561-566.

6. Iwahara T, Fujimoto J, Wen D, et al. Molecular characterization of ALK, a receptor tyrosine kinase expressed specifically in the nervous system. Oncogene. 1997;14:439-449.

7. Palmer RH, Vernersson E, Grabbe C, et al. Anaplastic lymphoma kinase: signaling in development and disease. Biochem J. 2009;420:345-361.

8. Bilsland JG, Wheeldon A, Mead A, et al. Behavioral and neurochemical alterations in mice deficient in anaplastic lymphoma kinase suggest therapeutic potential for psychiatric indications. Neuropsychopharmacology. 2008;33:685-700.

9. Weiss JB, Xue C, Benice T, et al. Anaplastic lymphoma kinase and leukocyte tyrosine kinase: functions and genetic interactions in learning, memory and adult neurogenesis. Pharmacol Biochem Behav. 2012;100:566-574. 
10. Morris SW, Kirstein MN, Valentine MB, et al. Fusion of a kinase gene, ALK, to a nucleolar protein gene, NPM, in non-Hodgkin's lymphoma. Science. 1994;263:1281-1284.

11. Chiarle R, Voena C, Ambrogio C, et al. The anaplastic lymphoma kinase in the pathogenesis of cancer. Nat Rev Cancer. 2008;8: 11-23.

12. Choi YL, Takeuchi K, Soda M, et al. Identification of novel isoforms of the EML4-ALK transforming gene in nonsmall cell lung cancer. Cancer Res. 2008;68:4971-4976.

13. Takeuchi K, Choi YL, Soda M, et al. Multiplex reverse transcriptionPCR screening for EML4-ALK fusion transcripts. Clin Cancer Res. 2008;14:6618-6624.

14. Rikova K, Guo A, Zeng Q, et al. Global survey of phosphotyrosine signaling identifies oncogenic kinases in lung cancer. Cell. 2007;131:1190-1203.

15. Takeuchi K, Choi YL, Togashi Y, et al. KIF5B-ALK, a novel fusion oncokinase identified by an immunohistochemistry-based diagnostic system for ALK-positive lung cancer. Clin Cancer Res 2009:15:3143-3149.

16. Jung Y, Kim P, Jung Y, et al. Discovery of ALK-PTPN3 gene fusion from human non-small cell lung carcinoma cell line using next generation RNA sequencing. Genes Chromosomes Cancer. 2012;51: 590-597.

17. Togashi Y, Soda M, Sakata S, et al. KLC1-ALK: a novel fusion in lung cancer identified using a formalin-fixed paraffin-embedded tissue only. PLoS One. 2012;7:e31323.

18. Wong DW, Leung EL, So KK, et al. The EML4-ALK fusion gene is involved in various histologic types of lung cancers from nonsmokers with wild-type EGFR and KRAS. Cancer. 2009;115:1723-1733.

19. Inamura K, Takeuchi K, Togashi Y, et al. EML4-ALK lung cancers are characterized by rare other mutations, a TTF-1 cell lineage, an acinar histology, and young onset. Mod Pathol. 2009;22:508-515.

20. Shaw AT, Yeap BY, Mino-Kenudson M, et al. Clinical features and outcome of patients with non-small-cell lung cancer who harbor EML4ALK. J Clin Oncol. 2009;27:4247-4253.

21. Rodig SJ, Mino-Kenudson M, Dacic S, et al. Unique clinicopathologic features characterize ALK-rearranged lung adenocarcinoma in the Western population. Clin Cancer Res. 2009;15:5216-5223.

22. Shinmura K, Kageyama S, Tao H, et al. EML4-ALK fusion transcripts, but no NPM-, TPM3-, CLTC-, ATIC-, or TFG-ALK fusion transcripts, in non-small cell lung carcinomas. Lung Cancer. 2008;61: $163-169$.

23. Koivunen JP, Mermel C, Zejnullahu K, et al. EML4-ALK fusion gene and efficacy of an ALK kinase inhibitor in lung cancer. Clin Cancer Res. 2008;14:4275-4284.

24. Zhang X, Zhang S, Yang X, et al. Fusion of EML4 and ALK is associated with development of lung adenocarcinomas lacking EGFR and KRAS mutations and is correlated with ALK expression. Mol Cancer. 2010;9:188.

25. Kim H, Yoo SB, Choe JY, et al. Detection of ALK gene rearrangement in non-small cell lung cancer. J Thorac Oncol. 2011;6: 1359-1366.

26. Yoshida A, Tsuta K, Watanabe SI, et al. Frequent ALK rearrangement and TTF-1/p63 co-expression in lung adenocarcinoma with signet-ring cell component. Lung Cancer. 2011;72:309-315.

27. Nishino M, Klepeis VE, Yeap BY. Histologic and cytomorphologic features of ALK-rearranged lung adenocarcinomas. Mod Pathol. June 29, 2012. [Epub ahead of print.]

28. Lee JK, Kim TM, Koh Y, et al. Differential sensitivities to tyrosine kinase inhibitors in NSCLC harboring EGFR mutation and $A L K$ translocation. Lung Cancer. 2012;77:460-463.

29. Pearson JD, Lee JK, Bacani JT, et al. NPM-ALK: the prototypic member of a family of oncogenic fusion tyrosine kinases. J Signal Transduct. July 18, 2012. [Epub ahead of print.]

30. Takezawa K, Okamoto I, Nishio K, et al. Role of ERK-BIM and STAT3survivin signaling pathways in ALK inhibitor-induced apoptosis in EML4ALK-positive lung cancer. Clin Cancer Res. 2011;17:2140-2148.
31. Katayama R, Khan TM, Benes C, et al. Therapeutic strategies to overcome crizotinib resistance in non-small cell lung cancers harboring the fusion oncogene EML4-ALK. Proc Natl Acad Sci USA. 2011;108: 7535-7340.

32. Heuckmann JM, Balke-Want H, Malchers F, et al. Differential protein stability and ALK inhibitor sensitivity of EML4-ALK fusion variants. Clin Cancer Res. 2012;18:4682-4690.

33. Piva R, Chiarle R, Manazza AD, et al. Ablation of oncogenic ALK is a viable therapeutic approach for anaplastic large-cell lymphomas. Blood. 2006;107:689-697.

34. Galkin AV, Melnick JS, Kim S, et al. Identification of NVP-TAE684, a potent, selective, and efficacious inhibitor of NPM-ALK. Proc Natl Acad Sci U S A. 2007;104:270-25.

35. Zou HY, Li Q, Lee JH, et al. An orally available small molecule inhibitor of c-Met, PF-2341066, exhibits cytoreductive antitumor efficacy through antiproliferative and antiangiogenic mechanisms. Cancer Res. 2007;67:4408-4417.

36. Christensen JG, Zou HY, Arango ME, et al. Cytoreductive antitumor activity of PF-2341066, a novel inhibitor of anaplastic lymphoma kinase and c-Met, in experimental models of anaplastic large-cell lymphoma. Mol Cancer Ther. 2007;6:3314-3322.

37. Bergethon K, Shaw AT, Ou SH, et al. ROS1 rearrangements define a unique molecular class of lung cancers. J Clin Oncol. 2012;30:863-870.

38. Kwak EL, Camidge DR, Clark J, et al. Clinical activity observed in a phase I dose escalation trial of an oral c-MET and ALK inhibitor, PF-02341066. J Clin Oncol. 2009;27 Suppl:148s.

39. Kwak EL, Bang YJ, Camidge DR, et al. Anaplastic lymphoma kinase inhibition in non-small cell lung cancer. $N$ Engl $\mathrm{J} \mathrm{Med}$. 2010;363:1693-1703.

40. Camidge DR, Bang YJ, Kwak EL, et al. Progression-free survival (PFS) from a phase 1study of crizotinib (PF-02341066) in patients with ALK-positive non-small cell lung cancer (NSCLC). Proc Am Soc Clin Oncol. 2011;29:2501.

41. Shaw AT, Yeap BY, Solomon BJ, et al. Effect of crizotinib on overall survival in patients with advanced non-small-cell lung cancer harbouring ALK gene rearrangement: a retrospective analysis. Lancet Oncol. 2011;12:1004-1012.

42. Camidge DR, Kono SA, Lu X, et al. Anaplastic lymphoma kinase gene rearrangements in non-small cell lung cancer are associated with prolonged progression-free survival on pemetrexed. J Thorac Oncol. 2011;6:774-780.

43. Shaw AT, Varghese AM, Solomon BJ, et al. Pemetrexed-based chemotherapy in patients with advanced, ALK-positive non-small cell lung cancer. Ann Oncol. August 10, 2012. [Epub ahead of print.]

44. Choi YL, Soda M, Yoshihiro Y, et al. EML4-ALK mutations in lung cancer that confer resistance to ALK inhibitors. $N$ Engl J Med. 2010;363:1734-1739.

45. Sequist LV, Waltman BA, Dias-Santagata D, et al. Genotypic and histological evolution of lung cancers acquiring resistance to EGFR inhibitors. Sci Transl Med. 2011;3:75ra26.

46. Doebele RC, Pilling AB, Aisner DL, et al. Mechanisms of resistance to crizotinib in patients with ALK gene rearranged non-small cell lung cancer. Clin Cancer Res. 2012;18:1472-1482.

47. Sasaki T, Koivunen J, Ogino A, et al. A novel ALK secondary mutation and EGFR signaling cause resistance to ALK kinase inhibitors. Cancer Res. 2011;71:6051-6060.

48. Tanizaki J, Okamoto I, Okabe T, et al. Activation of HER family signaling as a mechanism of acquired resistance to ALK inhibitors in EML4-ALK-positive non-small cell lung cancer. Clin Cancer Res. July 27, 2012. [Epub ahead of print.]

49. Yamada T, Takeuchi S, Nakade J, et al. Paracrine receptor activation by microenvironment triggers bypass survival signals and ALK inhibitor resistance in EML4-ALK lung cancer cells. Clin Cancer Res. 2012;18:3592-3602.

50. Katayama R, Shaw AT, Khan TM, et al. Mechanisms of acquired crizotinib resistance in ALK-rearranged lung cancers. Sci Transl Med. 2012;4:120ra17. 
51. Mehra R, Camidge DR, Sharma S, et al. First-in-human phase I study of the ALK inhibitor LDK378 in advanced solid tumors. J Clin Oncol. 2012; Suppl 30:Abstr 3007.

52. Sequist LV, Gettinger S, Senzer NN, et al. Activity of IPI-504, a novel heat-shock protein 90 inhibitor, in patients with molecularly defined non-small-cell lung cancer. J Clin Oncol. 2010;28:4953-4960.

53. Gambacorti-Passerini C, Messa C, Pogliani EM. Crizotinib in anaplastic large-cell lymphoma. N Engl J Med. 2011;364:775-776.

54. Butrynski JE, D'Adamo DR, Hornick JL, et al. Crizotinib in ALKrearranged inflammatory myofibroblastic tumor. $N$ Engl J Med. 2010; 363:1727-1733.

55. Mossé YP, Laudenslager M, Longo L, et al. Identification of ALK as a major familial neuroblastoma predisposition gene. Nature. 2008;455: 930-935.

56. George RE, Sanda T, Hanna M, et al. Activating mutations in ALK provide a therapeutic target in neuroblastoma. Nature. 2008;455:975-978.

57. Janoueix-Lerosey I, Lequin D, Brugières L, et al. Somatic and germline activating mutations of the ALK kinase receptor in neuroblastoma. Nature. 2008;455:967-970.
58. Sugawara E, Togashi Y, Kuroda N, et al. Identification of anaplastic lymphoma kinase fusions in renal cancer: large-scale immunohistochemical screening by the intercalated antibody-enhanced polymer method. Cancer. 2012;118:4427-4436.

59. Lin E, Li L, Guan Y, et al. Exon array profiling detects EML4-ALK fusion in breast, colorectal, and non-small cell lung cancers. Mol Cancer Res. 2009;7:1466-1476.

60. Montagut C, Galvan AB, Gallen M, et al. ALK chromosomal alterations in colon cancer patients. J Clin Oncol. 2010;28 Suppl 15: Abstr 10537.

61. Lipson D, Capelletti M, Yelensky R, et al. Identification of new ALK and RET gene fusions from colorectal and lung cancer biopsies. Nat Med. 2012;18:382-384.

62. Robertson FM. Gene amplification of anaplastic lymphoma kinase in inflammatory breast cancer. Presented at the AACR-NCI-EORTC International Conference on Molecular Targets and Cancer Therapeutics, November 12-16, 2011, San Francisco, CA.

\section{Publish your work in this journal}

Lung Cancer: Targets and Therapy is an international, peer-reviewed, open access journal focusing on lung cancer research, identification of therapeutic targets and the optimal use of preventative and integrated treatment interventions to achieve improved outcomes, enhanced survival and quality of life for the cancer patient. Specific topics covered in the journal include: Epidemiology, detection and screening; Cellular research and biomarkers; Identification of biotargets and agents with novel

Submit your manuscript here: http://www.dovepress.com/lung-cancer-targets--therapy-journa mechanisms of action; Optimal clinical use of existing anticancer agents, including combination therapies; Radiation and surgery; Palliative care; Patient adherence, quality of life, satisfaction; Health economic evaluations. The manuscript management system is completely online and includes a very quick and fair peer-review system. Visit http://www.dovepress.com/testimonials.php to read real quotes from published authors. 